\section{Preparing for the White House Conference}

\author{
By Stuart Forth \\ Member, ACRL Task Force on WHCLIS \\ Member, WHCLIS II Advisory Committee
}

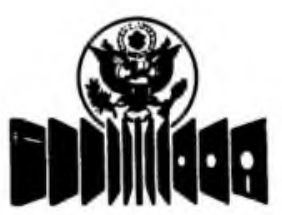

The White House Conference ON LIBRARY AND INFORMATION SERVICES 1991
The White House Conference on Library and Information Service II (WHCLIS) scheduled for the summer of 1991 will be similar in many ways to the 1979 WHCLIS. One similarity is likely to be its heavy emphasis on public libraries. Only a quarter of the delegates to the conference will be librarians and those of us in academia will be heavily out numbered by public and school librarians. The remaining three quarters of the delegates will represent the general public, trustees and friends of libraries, and public officials such as city council members, mayors, et al. who will be largely concerned with public libraries.

Our academic colleagues who are delegates may not be numerous, but they can still have an important effect on the Conference. The high quality of academic librarians being what it is, it is important that they speak up and contribute whatever proposals and ideas they may have on the issues being addressed. We must assert ourselves in those states and territories which have not yet held preWHCLIS conferences. For that matter, academic librarians individually and through state library associations can and should share their collective concerns and personal opinions with the WHCLIS staff; the sooner, the better.

Granting that the WHCLIS II Advisory Committee had a faltering start, once some basic personnel changes had been made, the Conference is shaping up well. NCLIS's new Chair Charles
Reid's appointments of Peter Young, Mrs. Jean Curtis, and Richard Akeroyd to key leadership positions, and the Chairs now appointed to various working committees (Program Planning, Resources, Public Relations, Delegate Education, et al.) are all strong indications of a healthy program.

Perhaps we should be thinking about a third national conference now! Looking ahead, it may be that ACRL, the Special Libraries Association, federal libraries, the bibliographic utilities folk, the nation's private colleges and universities and certainly the land grant universities should collectively start planning for the future of our academic libraries. ACRL is a logical and appropriate organization to consider this. Library directors in the Association of Research Libraries (ARL) could also provide leadership since their institutions are often on the cutting edge of new developments in information science.

There are indications that many states involved in pre-WHCLIS II activities already have or may put more emphasis on their needs for federal dollars than on imaginative and creative ways of addressing the three conference themes. To carry out WHCLIS themes effectively we must work closely with the information industry. This Conference can be beneficial to us and to our society. Certainly academic libraries can contribute significantly to it and to improving the world.

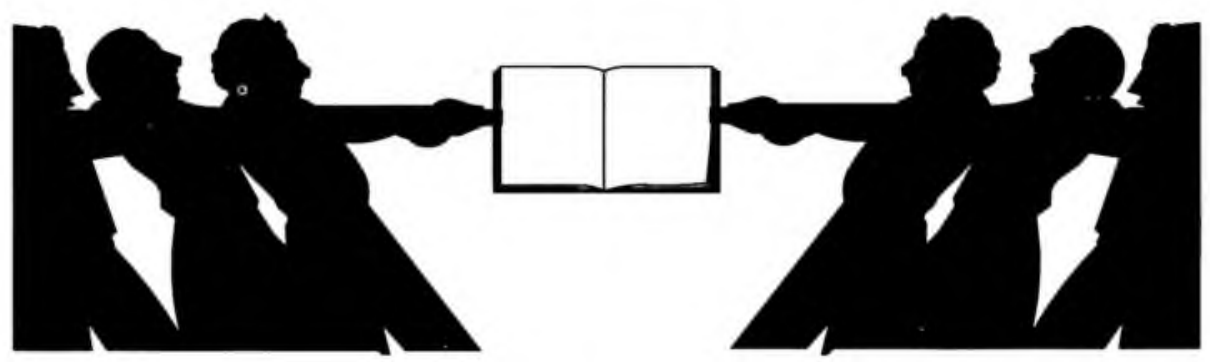

